\title{
La gran huelga azucarera de 1949 y la autonomia sindical. \\ El consenso acerca de la represión y la coerción.
}

\author{
Esteban Piliponsky \\ (UNT-CONICET) \\ epili50@gmail.com
}

Entre el 14 de octubre y el 29 de noviembre de 1949 tuvo lugar la huelga más larga y una de las más significativas de la historia de los obreros y empleados de la industria azucarera de todo el país. La presente investigación recapitula los acontecimientos más destacados de aquel conflicto, principalmente en Tucumán que fue su epicentro, y busca ubicarlo dentro del vínculo del sindicalismo azucarero y provincial en general, con el régimen peronista.

A pesar de la identificación de la mayoría de los trabajadores y de las organizaciones obreras del sector con el peronismo, durante todo el curso de la huelga el gobierno nacional, lejos de ubicarse como árbitro, lideró el enfrentamiento contra la misma. Apartó a la patronal de la disputa y, en cambio, movilizó a los diversos niveles del Estado para contrarrestar la medida: al Ministerio de Trabajo y Previsión para su ilegalización, al poder ejecutivo y legislativo provincial para presionar a los huelguistas, y a las fuerzas de seguridad para la represión. Sumó además algunos actores fundamentales con los que mantenía una línea directa: la CGT (Confederación General del Trabajo), en conjunto con otros sindicatos adictos, y la prensa oficialista. Una vez sofocada la huelga, el gobierno resolvió unilateralmente el principal reclamo obrero, el aumento salarial, haciéndose cargo de más de la mitad del mismo, y tomó el mando de las represalias individuales e institucionales, sin dar posibilidad a los damnificados de defenderse. Finalmente, mantuvo intervenida la FOTIA (Federación Obrera Tucumana de la Industria Azucarera) desde entonces hasta su caída, medida que habria de extenderse luego hasta los tiempos de Frondizi.

Con el fin de aislar la lucha azucarera el peronismo apeló a la noción hegemónica entonces de que todo diálogo con fuerzas "ajenas" al justicialismo atentaba contra el mismo. Ello por un lado, limitó el accionar de los azucareros, que se cuidaron de no expandir la huelga frente a un contexto favorable para hacerlo, limitándose sólo a pedidos de apoyo 
solidario moral o material; y, pese a eso, fue la excusa empleada para inculpar a toda la dirección del conflicto como "traidores" al régimen. A pesar de todo ello, el apoyo de las mayorías hacia el régimen peronista no se vio afectado seriamente, al menos en el ámbito público y electoral, más allá de algunas grietas que se pudieron haber ocasionado. Sin duda, el aumento de jornales otorgado a los trabajadores es uno de los factores para comprender aquello, pero no es el único. Gran parte de la explicación debe buscarse en el proceso vivido en los años previos por el movimiento y la clase obrera, tanto local como nacional, desde 1943.

Pese a que algunas voces dentro del propio peronismo se opusieron a la embestida que sufrieron los azucareros en su larga lucha de 1949, la identificación con el gobierno de Perón se mantuvo firme, imponiéndose asi un consenso acerca de su accionar durante la huelga. La fuerte adhesión obtenida por este movimiento implicaba otorgarle legitimidad para perseguir, reprimir y expulsar de los sindicatos y del partido a todos aquellos que la jerarquía consignase como opositores a la "revolución". Este accionar se fue produciendo en forma reiterada y debe tener un lugar destacado en cualquier explicación de aquellos años, lo cual no sucede con la mayor parte de la historiografia hegemónica sobre el período. "La gran huelga azucarera" de 1949, como se la conoce, implicó en su desenlace un hito en el proceso de ataque a la autonomía del movimiento obrero, produciendo un cambio cualitativo en el gremialismo tucumano. Pero la hipótesis de la que parte este trabajo es que dicha embestida fue la continuidad de una tendencia ya existente.

\section{Los antecedentes de la huelga}

Desde su fundación a mediados de 1944, la FOTIA se transformó en una de las organizaciones obreras de segundo grado más grandes del país, con la particularidad de ser de las pocas ubicadas fuera de la Capital Federal y sus alrededores. En la época de zafra representaba alrededor de 150.000 trabajadores, que llegaban a 180.000 sumando a los empleados nucleados en la FEIA (Federación de Empleados de la Industria Azucarera). Estos se repartian entre Tucumán, Salta, Jujuy y Santa $\mathrm{Fe}$, con una fuerte concentración en la primera de éstas por ser el mayor centro productivo superando el $80 \%$ de lo fabricado en el país.

La FOTIA se creó al calor del proceso de sindicalización impulsado desde el gobierno nacional. Se construyó sobre la base de los sindicatos existentes en la actividad, divididos entre socialistas, comunistas y sindicalistas; y mediante la gestión en el poder ejecutivo de la provincia de un grupo local de católicos adscriptos a la Doctrina Social de la Iglesia, seguidores del falangismo español, y proclives a la sindicalización de tipo corporativa y confesional. Sin duda la organización les dio fuerza a los 
obreros en sus lugares de trabajo contra la patronal pero en simultáneo se abocó, en alianza con el gobierno, a perseguir a todo aquel que fuese sospechado de mínima disidencia.

A pesar de ser fundamental en la estructuración del peronismo en la provincia, la federación representaba en algún punto un obstáculo a la permanente búsqueda de jerarquización sindical y política que caracterizaba al mismo. Siempre fue díscola respecto a la delegación regional de la CGT en Tucumán, como así también en el vínculo con los demás sindicatos. En tanto, la distancia geográfica era un impedimento para ejercer un control más directo por parte de la confederación a nivel nacional. En el terreno político, la FOTIA buscó posicionarse como un actor independiente dentro del Partido Laborista primero, y peronista después. Ni en el aspecto gremial ni en el partidario logró tener la supremacía pretendida, pero alcanzó un peso propio importante. Muchos funcionarios electos y designados provenian de sus filas, en algunos casos en simultáneo con los cargos gremiales. En 1949 el entonces secretario general, Lorenzo Obdulio Rivarola, y el secretario de actas, Carlos Márquez, integraron la Asamblea Constituyente. El primero además era diputado provincial. Estos son solo los ejemplos más destacados de un sector de los sindicalistas que, a pesar de las controversias vigentes sobre prescindencia, tenían en paralelo una carrera politica. Otros abandonaron la tarea gremial para abocarse netamente a la vida partidaria.

Hasta 1948 la FOTIA se rehusó sistemáticamente a utilizar la huelga como mecanismo de presión y negociación. Las excepciones fueron las jornadas de octubre de 1945, y meses después la pelea por el aguinaldo en enero de 1946. Luchas que, más allá de su legitimidad entre la mayoria de los sectores obreros, no se originaron en cuestiones internas de la actividad y se produjeron en un contexto particular. La federación sólo amenazó con "huelgas en principio" que nunca se ejecutaron y buscó frenar las declaradas por sus filiales, que fueron numerosas en ese período, imponiendo siempre la vía institucional, en muchos casos dilatada adrede por el gobierno y la patronal. Pero el retraso salarial de los azucareros y la crisis en el sector, junto al aumento de costo de vida y los límites de la politica distributiva que comenzaron a avizorarse, modificó este accionar. En octubre de 1948 la FOTIA paró por aumentos salariales levantando la medida tras la presión del gobierno, que se comprometía a darle una solución. A comienzos de 1949 nuevamente la federación declaró la huelga por los despidos en masas que se produjeron. Se acordó la limitación de los industriales a las cesantías masivas (aunque no a las individuales), y un aumento del $20 \%$ en los salarios que, aunque aquietó las aguas, fue claramente insuficiente.

Paralelamente, el gobierno aspiraba a quitar las compensaciones otorgadas al sector para apoyar su sostenimiento, las que desde 1945 
se destinaban en gran parte al pago de salarios. Esto fue aprobado por el congreso nacional en septiembre de 1949, permitiendo a cambio un aumento en el precio del producto al consumidor final del $110 \%$. Pero este porcentaje debe ser matizado por lo rezagado que se encontraba el mismo. La Ley Saavedra Lamas de 1912 impuso un límite de \$ 0,41 el kilogramo que se mantuvo hasta terminada la Segunda Guerra Mundial. En el mismo período la carne aumentó de \$0,32 a \$0,85 el kilo. La política del Estado en la materia "se propuso mantener indefinidamente deprimido el precio del azúcar producido en el país" (Pucci, 2007: 4142). Al momento de la quita de subsidios este ya había sido levemente aumentado a $\$ 0,50$ y con la anulación de los mismos pasaba a $\$ 1,10$. De todos modos, en comparación con el crecimiento de otros productos y de los costos en general, no puede decirse que el peronismo haya anulado la brecha del histórico atraso del precio del azúcar.

\section{El estallido de la huelga y la intervención}

A comienzos de octubre de 1949 la comisión de delegados de la FOTIA que tramitaba en Buenos Aires el aumento de salarios fracasaba en sus objetivos. Perón se negaba a recibirlos, y Eva Perón les anticipaba que el aumento oscilaría en el $18 \%,{ }^{1}$ cifra luego ratificada por cañeros e industriales en la mesa paritaria reunida en el Ministerio de Industria y Comercio de la Nación. Este monto era muy lejano a la aspiración del $60 \%$ pedida por los trabajadores, en su afán de equiparar sus sueldos con los del resto de los obreros industriales del país. La conflictividad acarreada y el aumento del precio del producto generaron una presión de las bases por acordar una suba de jornales importante durante aquel año. Promediando octubre, 7 de los 28 ingenios tucumanos habian concluido la zafra, y el resto estaba próximo a terminarla. ${ }^{2}$ Por ello, frente a la estrategia empresarial de dilatar las negociaciones, el día 11 la FOTIA emplazó a industriales y cañeros a dar una respuesta satisfactoria hasta el 14 de octubre o entrarian en paro, lo cual finalmente sucedió.

El reclamo era el aumento de los salarios según el proyecto de estatuto del azúcar entregado por la federación un mes antes, mientras dejaban los demás aspectos de las condiciones de trabajo para discutirlas en la paritaria de 1950. Sin embargo, además de lo monetario se sumaba un punto dirigido al gobierno:

Considerando que el Centro de la Producción Azucarera se encuentra en la provincia de Tucumán, solicitar al Exmo.

1. La Gaceta, 5 de octubre de 1949.

2. La Prensa, 14 de octubre de 1949. 
Señor Presidente de la Nación General Juan Perón, que la Dirección del Azúcar sea trasladada a esta provincia, para una mejor y mayor efectividad de sus funciones específicas como corresponde a todo organismo del Estado. ${ }^{3}$

Sumado a la demanda salarial, la FOTIA consideró necesario realizar este reclamo histórico de todos los actores vinculados a la industria en la provincia, desoído por el peronismo así como por sus sucesores que siempre centralizaron el aparato burocrático encargado de regular la actividad en la Capital Federal, hasta nuestros días.

El 14 de octubre se declaraba la huelga. A los obreros se sumaron los empleados de la actividad, nucleados en la FEIA. Ambas federaciones formaron un comité intergremial que fue replicado en cada fábrica azucarera. Tanto FOTIA como FEIA centraron su discurso en el ataque exclusivo contra industriales y cañeros remarcando que la huelga, lejos de significar un embate contra el gobierno era, por el contrario, un aval a su gestión. Ello implicaba un rechazo explícito a todo apoyo moral y material proveniente de partidos políticos o sectores de la sociedad civil que fuesen opositores, particularmente del PC, entendido como "extraño de la conciencia nacional" y por ende del "sentimiento de los obreros argentinos". Ante las primeras declaraciones de este tipo, la intergremial refutaba:

El actual movimiento resuelto por los empleados y obreros de la Industria Azucarera es de carácter gremial, consecuente con los principios para los que fueron creadas ambas Federaciones, razón por la cual en ningún momento podemos aceptar tutelas o defensores politicos extraños al movimiento, [...] al mismo tiempo esta COMISION expresa que sin desmadre de las mejoras solicitadas estamos y estaremos con la Obra de Gobierno de nuestro Excmo. Señor Presidente de la Nación General Juan Domingo Perón, Líder de los Trabajadores Argentinos, en quien confiamos y esperamos, que ante la intransigencia de los industriales y cañeros, sabrá dar una solución justa a nuestros pedidos. ${ }^{4}$

En tanto, la comisión intergremial admitía y alentaba las proclamaciones de solidaridad llegadas desde numerosos Centros Femeninos María

3. Resolución de FOTIA, 11 de octubre de 1949. Los documentos sindicales nombrados en el trabajo se encuentran en el archivo del Partido Comunista (PC) y se hallaban inexplorados hasta aqui, al menos por las investigaciones académicas.

4. Comunicado de la Comisión Intergremial de FOTIA y FEIA, 18 de octubre de 1949. 
Eva Duarte de Perón, en muchos casos formados por las esposas de los obreros azucareros, como así también de centros peronistas.

Sin embargo, la actitud gubernamental fue de inmediato rechazo a la huelga. Apenas declarado el cese de actividades, se cortaron las negociaciones y el Ministerio de Trabajo y Previsión emplazó a las federaciones a retornar al trabajo antes de atender cualquier demanda. ${ }^{5}$ El Correo Nacional se negó a enviar los telegramas a las filiales de las demás provincias comunicando la huelga, lo que retrasó unos días la propagación de la medida, y la prensa oficialista criticó duramente la misma. La Época fue uno de los diarios más hostiles, caracterizando el paro como un ataque a la revolución motivado por el comunismo. ${ }^{6}$

Hacia el 20 de octubre ya se habian plegado a la huelga todos los ingenios del país, 37 en total, los cuales incluian además de los tucumanos a los de las provincias de Jujuy, Salta y Santa Fe. El sindicato de obreros del ingenio La Fronterita declaró que creía "firmemente que esta huelga es el resultado lógico de tres años de engaños que hemos venido soportando, porque $40 \%$ de aumento que han experimentado nuestros salarios, no compensa el costo de la vida, elevado en igual lapso en más del 200\%". Los responsables absolutos de esta situación según aquellos trabajadores eran industriales y cañeros, mientras el peronismo intentaba revertir tal escenario. ${ }^{7}$

Tras el rechazo obrero al emplazamiento de volver al trabajo, el 23 de octubre se declaraba la ilegalidad de la huelga. La policía clausuró los locales de la FOTIA y FEIA y los de todas sus filiales sin mediar orden judicial, lo cual era un abuso de autoridad pues estas tenian aun la personería gremial. En Jujuy se encarcelaron a importantes dirigentes, anticipando lo que sucedería un mes después en Tucumán.

Si bien la falta de fuentes nos limita para conocer los debates internos entre los obreros, podemos inferir algunos contrapuntos en base a lo existente. A pesar de la prohibición policial, luego de la ilegalización muchas filiales pudieron reunirse al igual que ambas federaciones para recibir sus mandatos, aunque no en sus sedes debido a las clausuras. En la asamblea de la FOTIA, que debió sesionar bajo la presencia policial, surgieron algunas discrepancias. El delegado del ingenio Aguilares recordó que había advertido sobre la posibilidad de que el gobierno se enfrentara a la huelga, lo que fue desestimado en su momento por la fe de los trabajadores en Perón. Su intervención fue rechazada, solicitándole que se limitara a explicitar la posición de su filial. Luego el delegado del ingenio Concepción transmitió en su informe la siguiente

5. La Gaceta, 15 de octubre de 1949.

6. La Época, 15 de octubre de 1949.

7. La Gaceta, 20 de octubre de 1949. 
exhortación: "Advierten, además, los afiliados, que los dirigentes de la FOTIA no persistan en recomendar como aconsejable el levantamiento del paro, porque, en ese caso, se volverán contra ellos". ${ }^{8} \mathrm{Al}$ fin, la asamblea ratificó la huelga por unanimidad.

El 27 de octubre se decretaba desde el gobierno la caducidad de las personerias gremiales de FOTIA y FEIA. La CGT, que no se había manifestado públicamente sobre el conflicto, envió a la provincia tres interventores: Antonio Ferrari, que ya habia sido interventor de la CGT local en 1947, Julio Berón y Héctor Brown. La intromisión fue ampliamente rechazada por los trabajadores azucareros, aunque la habian presentido: el 25 de octubre, el Sindicato de Obreros Fleteros de La Reducción despachaba una misiva manuscrita a la FOTIA solicitándole que, ante el rumor de intervención, nombrase comisiones directivas secretas a lo largo de la provincia para mantener informados a los obreros, sobre todo frente a la prohibición de reunirse en los locales gremiales. ${ }^{9}$ La intervención, además, despertaba una vieja resistencia provincial a la imposición de dirigentes y funcionarios emanados desde el poder central del país.

Los interventores llegaron con una propuesta extorsiva: demandaron a los trabajadores la vuelta al trabajo a cambio de un aumento "como mínimo" del 30\%, y cinco puntos que sólo darian a conocer una vez levantada la medida. Al aterrizar en la provincia se instalaron en la Casa de Gobierno local, donde fueron recibidos por el primer mandatario, y convocaron a presentarse a los sindicalistas del medio. Su acogida fue similar a la que habria tenido una comitiva de funcionarios públicos, y la dirección del conflicto fue dejada en sus manos, claro que en representación de la posición estatal. Los emisarios metropolitanos entablaron la negociación con la comisión intergremial de las dos federaciones, aunque catalogando a sus miembros en las declaraciones públicas como "ex dirigentes", ya que habian perdido su condición tras la intervención. Al mismo tiempo, rechazaron el pedido de los azucareros de acompañarlos a los lugares de trabajo para hablar directamente con los trabajadores y exponerles la propuesta. Ambas partes percibian lo endeble de la misma y el gran acatamiento que tenía la huelga.

De todos modos los cegetistas impulsaron una fuerte campaña de radiodifusión, aprovechando el control de ese medio masivo de comunicación, remarcando la responsabilidad de los obreros en la campaña gubernamental de aumentar la producción e invocando la confianza en Perón, quien daría una "solución justa" siempre y cuando se terminara con la medida de fuerza. Además, alentaron a los industriales para que

8. La Gaceta, 27 de octubre de 1949.

9. Carta a FOTIA del Sindicato La Reducción, 25 de octubre de 1949. 
comenzasen a tocar las sirenas de los ingenios llamando al trabajo, como en días normales, lo cual se mantuvo a lo largo del conflicto. La CAT (Compañía Azucarera Tucumana), fue más allá y envió telegramas personales emplazando a varios obreros a retornar al trabajo bajo amenaza de exoneración. Mientras tanto, la represión policial aumentó con el paso de los dias. A la clausura de los locales sindicales y la prohibición de reunirse, se le sumó la veda para realizar marchas y manifestaciones públicas. En algunos pueblos azucareros se realizaron igual, como en Bella Vista el 27 y en Concepción el 31 de octubre, y ambas terminaron con represión y heridos. El objetivo de la fuerza pública, al igual que en la huelga de los mismos azucareros en 1948, era impedir que se produjesen movilizaciones hacia la capital provincial, lo cual se logró.

El maltrato de los interventores hacia los desplazados de FOTIA y FEIA pretendió ser atemperado en un primer momento, mediante el reconocimiento de palabra de sus "buenas intenciones". Pero tal situación cambió apenas a los dos días del arribo de los comisionados cegetistas. Según el posterior informe de la intergremial, en una reunión que tuvo lugar el 30 de octubre, Berón habría reprendido a las federaciones manifestando que "parecía mentira de que no fueran cuidados los intereses de los industriales, que se encontraban tirados, que en forma irresponsable y salvaje, se habian malogrado cuantiosos intereses". ${ }^{10}$ Esta defensa explícita de la patronal junto a la noticia falsa difundida por los interventores respecto al levantamiento del paro en Salta y Jujuy, generó la primera disputa fuerte entre la CGT y los azucareros.

Tras este choque la intergremial retomó la iniciativa presentando un petitorio que podria resumirse en: levantamiento de la intervención, no represalias, aumento del $60 \%$ y 15 días de plazo para discutir el estatuto presentado por los trabajadores. La respuesta de la CGT fue un ataque abierto acusando a la huelga de estar manejada por opositores políticos, especialmente comunistas. Se sumó en la embestida el propio secretario general de la confederación, José Espejo, quien advirtió que daría a conocer a los infiltrados "en el momento oportuno". ${ }^{11}$

\section{La relación de la FOTIA con los demás sindicatos provinciales}

El vínculo de la FOTIA con los restantes sindicatos de la provincia era complejo. Ya antes de su creación, el lazo entre las agrupaciones existentes por fábrica o zona cañera con las de la ciudad era dificultoso por una cuestión geográfica, lo que complicaba también el nexo entre

10. La Gaceta, 30 de octubre de 1949.

11. La Gaceta, 4 de noviembre de 1949. 
un ingenio y otro. Desde la fundación de la federación, por su tamaño en cuanto a cotizantes, por su estructura de organización de segundo grado y por su carácter interprovincial tendía a relacionarse más con la CGT y el gobierno a nivel nacional antes que local.

Sin embargo todo ello no es suficiente para explicar la falta de convergencia, y en muchos casos de solidaridad, entre las huelgas urbanas de los diferentes gremios de la capital tucumana y la de los azucareros, siendo que los primeros lograron confluir en varias ocasiones. Analizamos en otro escrito un ejemplo de tal situación, durante la campaña electoral para los comicios de 1946 en el marco de las luchas por el aguinaldo (Piliponsky, 2011a). En 1949 volvía a repetirse ese desencuentro.

El 11 de octubre de 1949, apenas 3 días antes de que estallase el conflicto azucarero, comenzaba una huelga de los obreros municipales de la capital provincial, junto con los trabajadores del principal matadero de la ciudad, que pertenecía a la comuna. Demandaban una recomposición salarial hasta las paritarias del año 1950, que los equiparase con el resto de los empleados públicos nacionales, más una ampliación del salario familiar. El conflicto fue ilegalizado y 80 obreros fueron cesanteados, presionándolos para volver al trabajo, aunque luego se dejó esa medida sin efecto. La municipalidad intentó sin éxito colocar obreros rompehuelga, lo cual generó numerosos conflictos callejeros por la resistencia de los trabajadores en paro. Toda esta situación mantenía en vilo a la opinión pública capitalina, como así también al ejecutivo provincial y a los demás gremios locales. Al arribar los interventores de la FOTIA, el 27 de octubre, se posicionaron también como intermediarios del conflicto municipal, puesto que la delegación local de la confederación ya había fallado en ese intento.

La disputa se extendió hacia otros sindicatos, quienes crearon una comisión intergremial y decretaron una huelga general que se llevó a cabo el 31 de ese mes, pese a la fuerte oposición del gobierno y de la CGT local y nacional. Mientras se negociaba con la mencionada intergremial, muchos de sus miembros fueron demorados en el subsuelo de la Casa de Gobierno, donde funcionaba la estación central de la policía, aunque siguieron siendo considerados por las autoridades como interlocutores, mientras los mantenía presos e incomunicados.

La huelga general en la ciudad duró dos días y participaron los gremios más importantes, salvo el de empleados de comercio que, junto a otras agremiaciones menores, respetaron la línea cegetista. La mayoría de las demandas de los municipales fueron atendidas. El conflicto dejó diezmado al secretariado general de la CGT local, ya que muchos de sus miembros apoyaron la huelga y renunciaron al mismo. Además, en respuesta a la medida de fuerza, algunos sindicatos fueron intervenidos o sufrieron la intromisión directa de los gremialistas metropolitanos que 
actuaban en la ciudad y, luego de solucionado el conflicto azucarero, la propia filial local de la confederación quedó bajo su dominio.

Un hecho sumamente grave ocurrido en el curso del conflicto fue el asesinato del obrero Dardo Trassi, un chofer que se encontraba de paro junto a su sindicato. Trassi apedreó un colectivo como parte de las medidas de boicot usadas contra los rompehuelga que intentaban hacer funcionar algunos servicios. La unidad estaba custodiada por una agente policial que bajó de la misma, lo persiguió y lo acribilló. En un contexto de gran represión y encarcelamientos, su asesinato despertó una profunda ira entre los huelguistas, agudizada por la tentativa oficial de presentar el hecho como un crimen por venganza personal ajeno al tema obrero.

Lo paradójico, aunque no inédito, es que en los días en que simultáneamente se encontraban en lucha los azucareros y los municipales, y luego en las dos jornadas de huelga general en la capital provincial en apoyo a estos últimos, no hubo lazos ni espacios de confluencia entra ambos sectores. Sólo la muerte de Trassi despertó comunicados de solidaridad de algunos sindicatos azucareros, pero con muy poca trascendencia.

A los factores mencionados, que distanciaban a los trabajadores de la ciudad con los azucareros, debemos agregarles otros elementos que ayudan a comprender tal situación. Parte de la estrategia gubernamental de ataque contra las huelgas era eliminar toda posibilidad de huelga solidaria. Al declarar los azucareros el cese de actividades, varias zonas rurales con producciones diversas donde la caña era una de ellas, se adhirieron a la medida. El Sindicato de Obreros Forestales de Villa Benjamín Aráoz y de la Tablada, y los obreros de la finca arrocera Entre Ríos (que tenía un sector cañero), fueron alguno de éstos. Sin embargo, las autoridades presionaron para impedir el apoyo, remitiéndose a una resolución de 1948 que prohibía los paros en fincas o establecimientos rurales en que se desarrollen tareas industriales, cuando éstas se producian en solidaridad con alguna de las ramas del establecimiento. Dichos trabajadores decidieron acatar la orden, salvo los obreros dedicados a la tarea cañera dentro de cada finca.

De todos modos no sólo la presión oficial, a la cual debemos sumar la de la CGT, justifica el aislamiento de la FOTIA en su huelga, ya que en el seno de su misma conducción se sostenía la postura de no extender ni agrandar la disputa hacia otros sectores. Y aunque emitió varios pedidos de solidaridad, se negó a coordinar acciones con los trabajadores citadinos también en huelga.

Desde un primer momento la FOTIA fue acusada de sabotear la obra del gobierno, pese a que la federación se proclamaba como aliada del oficialismo. La negativa a vincular su lucha con los demás gremios 
tenía como objetivo reafirmar dicha lealtad con el peronismo, actitud que como veremos más adelante, no resultaria suficiente. En tanto, la solidaridad con otros sectores del movimiento obrero era pregonada por los diversos grupos opositores del campo partidario y sindical, por ejemplo el PC (Arnedo Álvarez, 1950: 85-86). En ese sentido, el rechazo absoluto al apoyo de factores ajenos al gremialismo se complementaba con una muy limitada acción intersindical.

Esta situación le permitió al gobierno y a los enviados de la CGT mantener el nivel de conflictividad controlado con los azucareros, mientras su huelga coexistía con la de los municipales. Más aun, cuando esta última se volvió más beligerante al hacerse general. Saldada la misma y cumplidos ya 20 dias desde el comienzo del paro de la FOTIA, el gobierno nacional puso en práctica una estrategia mucho más agresiva aun, alineando en ella al poder ejecutivo y legislativo provincial, la CGT y las fuerzas represivas.

\section{Contra la gran huelga, la gran represión gubernamental}

Los primeros días de noviembre, una vez solucionada la huelga general en solidaridad con los municipales, viajaron a Buenos Aires el gobernador Carlos Dominguez y dos de los tres interventores de la CGT: Berón y Brown. El primero se entrevistó con Perón y los otros con la cúpula cegetista. Se pergeñó alli una fuerte ofensiva para lograr que los azucareros levantasen su medida de fuerza antes de conocer las mejoras ofrecidas, en las cuales se empeñaba la palabra del presidente de la nación como garantía de su justicia. También saldría entonces desde las autoridades centrales la decisión de mantener la intervención sobre FOTIA, FEIA y todas sus filiales, luego del conflicto.

La embestida contra la huelga azucarera cobró entonces cierta analogía con la táctica de una invasión militar. En primer lugar, a la propaganda radial se le sumó un "bombardeo" de panfletos exhortando la vuelta al trabajo, lanzado por avionetas sobre las viviendas de los trabajadores. ${ }^{12}$ En simultáneo se buscó crear una "cabecera de playa" en el ingenio tucumano de La Esperanza (existía otra fábrica azucarera homónima en Jujuy, pero sin vínculos con esta), presionando para que volviese al trabajo más allá de la resolución de la intergremial.

La Esperanza había cerrado sus puertas a comienzos de 1949 por quiebra. La FOTIA realizó una lucha por la defensa de los puestos de trabajo de esa fábrica y de otras que habían realizado despidos, como mencionamos anteriormente. El ejecutivo provincial decidió salvar la empresa haciéndose cargo de la gestión de la misma mediante el

12. La Gaceta, 10 de noviembre de 1949. 
OFEMPE (Organismo Financiador de Empresas Mixtas Privado Estatal). La presencia de funcionarios públicos en su dirección generaba una presión directa contra los huelguistas en ese ingenio. A los pocos dias de comenzado el conflicto, el presidente de su sindicato, Armando Bulacio, enviaba una carta a la FOTIA advirtiendo el temor entre los afiliados de que el paro pudiera provocar el levantamiento de la incautación, y pidiendo que la federación contemple esta situación..$^{13}$ El 9 de noviembre, tras una presión mucho más fuerte por parte del gobierno provincial, se lograba convencer a un grupo de obreros que retornasen al trabajo asegurándoles la "libertad de trabajo", a pesar de la oposición del sindicato. Aunque en un comienzo fueron muy pocos los que decidieron el retorno, La Esperanza se volvió la punta de lanza y el ejemplo que buscaron replicar el gobierno y la CGT en los demás ingenios.

Finalmente, la estrategia de esta ofensiva contra la huelga azucarera implicaba ingresar al propio territorio, es decir el contacto directo con las bases para buscar quebrar la unidad de los trabajadores. Sin duda esto era lo más complejo. Los interventores de la CGT, luego del regreso desde Buenos Aires de Berón y Brown, convocaron al comité intergremial a una reunión. En ese encuentro varios miembros de la FOTIA ofrecieron su renuncia, empezando por Rivarola, su secretario general. Pero los emisarios metropolitanos intentarian, por última vez, que fuesen los miembros de las comisiones directivas de ambas federaciones los que presionasen a sus filiales y a sus bases a levantar el conflicto en nombre de la lealtad con Perón, pues ya era evidente la imposibilidad de terminar la huelga solo con la decisión de la intergremial.

Por ello cedieron al pedido de los azucareros de permitir la reunión de las filiales para considerar la oferta de levantar la medida y en un plazo de 60 horas, según acordaron, se dieran a conocer las mejoras prometidas. En realidad, la restricción para realizar asambleas obreras había sido ordenada por la policía, pero el vínculo de esta con los interventores era directo. Así relata la prensa local la gestión de dicha autorización: "Telefónicamente Ferrari [interventor de la FOTIA] pidió y obtuvo permiso para las reuniones de sindicatos y de las autoridades de la FOTIA y FEIA". ${ }^{14}$ Lo que la intergremial pedía desde la ilegalización, era conseguido con esta facilidad por los cegetistas. Además se notificó la decisión traída desde la Capital Federal de que la intervención continuaría luego de solucionada la huelga, hasta que se "aclarasen las respectivas actuaciones" y se reorganizara el gremio. Es decir que los interventores estaban anunciando que, en cierta medida, el futuro

13. Carta a FOTIA del Sindicato La Esperanza, 18 de octubre de 1949.

14. La Gaceta, 13 de noviembre de 1949. 
gremial de aquellos delegados estaría en sus manos (aunque luego la razzia fue mucho mayor de la que se podia imaginar hasta ese momento).

Al día siguiente, el 13 de noviembre, se reunió nuevamente la asamblea de delegados, ya con mandato de cada filial y con un número mucho más grande de azucareros. El encuentro fue muy ríspido con los interventores, con la policía que se hizo presente y lograron que se retirase de la reunión, e incluso entre los propios delegados. La mayoría de los sindicatos mocionó continuar la huelga, lo que luego de tantos dias y con las mencionadas presiones, solo puede explicarse por una gran cohesión y convencimiento de las bases. La medida debía terminarse únicamente si se obtenían respuestas concretas o, cuestión novedosa sugerida por algunas filiales, si Perón lo solicitaba personalmente. Sin embargo, la posición no fue unánime y comenzaron a develarse algunas fisuras. Los obreros del Ingenio Corona y obreros y empleados del ingenio Santa Rosa, llevaban la posición de levantar la huelga, aunque acatarían lo que decidiese la mayoría. La delegación del ingenio Santa Lucía y la de trabajadores del surco de Los Ralos estaba dividida. En tanto los obreros de La Esperanza no llevaron mandato por no haber llegar a un acuerdo en su asamblea.

Es complejo dilucidar si los interventores tenían puestas reales esperanzas en que aquella asamblea diera fin al conflicto, o fue solo un artilugio político para aparentar el agotamiento de todas las instancias posibles con la intergremial. Sin duda, con mayor o menor grado de representatividad, estos delegados seguían teniendo legitimidad entre las bases. Lo cierto es que tras la reunión los cegetistas pudieron "justificar" el ninguneo al que someterian a las autoridades de FOTIA y FEIA de aquí en adelante. Además obtuvieron una clara muestra de las posiciones de cada sindicato y de sus delegados, las cuales estaban seguramente llenas de matices. El comunicado de los interventores luego de ratificarse la continuidad de la huelga, decía:

Quedaron demostrados una vez más los principios de verdadera democracia sindical que caracteriza a la CGT, la cual dio a los ex dirigentes la oportunidad para que se pronunciaran sobre condiciones impuestas, interpretando el mandato del Presidente de la Nación, y que, ante la intransigencia de los mismos, se dirigen [los interventores] directamente a los obreros, a fin de ratificar el llamamiento para que ocupen sus puestos en los lugares habituales de trabajo. ${ }^{15}$

Era necesario ahora encontrar a los que podrian vehiculizar aquel trato directo con los trabajadores. Ese papel sería encomendado al bloque 
de legisladores provinciales peronistas. Muchos de los diputados y senadores tucumanos del justicialismo eran obreros provenientes del ámbito sindical, y particularmente del azucarero. Pero se mostraron mucho más permeables a la presión gubernamental que las autoridades de FOTIA y FEIA, quienes mantenían mayor cercanía con las bases. El 16 de noviembre Domínguez organizó una reunión con algunos miembros de su gabinete, los interventores metropolitanos y el bloque de legisladores de su partido. Al salir, estos últimos lanzaron un comunicado exhortando a la vuelta al trabajo en un tono paternalista que llamaba la atención, y fue repudiado por numerosos huelguistas en los dias siguientes. Aunque llevaba la firma de todos los legisladores del bloque, tres de ellos se excusaron argumentando que no habian participado en el mismo: el senador Delfor Gallo y los diputados Manuel Osores y Lorenzo Obdulio Rivarola, quien era además secretario general de la FOTIA. Gallo y Rivarola serian expulsados del bloque y este último también del partido, en tanto Osores fue indultado tras su pedido de disculpas.

Lo importante, más allá del comunicado, fue la decisión de diputados y senadores de entablar una relación directa con los huelguistas. Como reseñaba un diario capitalino: "Se sabe [...], que los legisladores han decidido realizar excursiones por el interior de la provincia, a fin de ponerse en contacto con los trabajadores de los ingenios, con el propósito de persuadirlos de la necesidad de reanudar la faena, como medida previa a la solución anhelada". ${ }^{16}$ Estos convocaban a grupos de trabajadores y los acompañaban a la Casa de Gobierno para que hablasen directamente con los interventores. Realizaron asambleas paralelas a los sindicatos, y en algunos casos lograron incluso el apoyo de las autoridades de la organización, aunque ello no significaba conseguir la mayoría para terminar con el paro. Tiempo después de concluida la huelga, un grupo de obreros de Bella Vista (cuyo sindicato estaba intervenido como todos los demás), criticaba que la lucha se había politizado y ponían como ejemplo el accionar del diputado Luis Roberto Castro. Sostenían que había colaborado con la huelga, hasta el punto de poner a disposición un jeep de una repartición pública y una camioneta de su propiedad, con la que los huelguistas recorrian las colonias. Pero "apareció después como uno de los firmantes de una exhortación de legisladores con respecto a la vuelta al trabajo" y comenzó a utilizar esos mismos vehículos para lograr ese objetivo, lo cual "resultó sugestivo frente a su anterior colaboración en favor de conflicto". ${ }^{17}$ Quizás el caso del diputado Castro sea paradigmático del derrotero de varios de estos legisladores.

La misión de diputados y senadores estaba apuntalada desde dis-

16. La Prensa, 19 de noviembre de 1949.

17. La Gaceta, 15 de diciembre de 1949. 
tintos lugares. El mismo día que se dio a publicidad su comunicado, se anunciaba que el ingenio La Esperanza volvía al trabajo en su totalidad. La intergremial y muchos otros sindicatos criticaron fuertemente esa falta de solidaridad, recordando que pocos meses antes todos los azucareros habian salido a defender los puestos de trabajo de aquellos obreros. Pero la presión para estos asalariados se hizo insostenible. De todos modos, a pesar de ser el primer ingenio en la provincia que regresaba a las labores, Bulacio, presidente de su sindicato, no se salvaría de ser acusado tiempo después por Perón como uno de los "traidores".

Junto al retorno en La Esperanza, que había empezado con una vuelta parcial de alguno de sus obreros, el gobernador ratificaba públicamente que aseguraría la "libertad de trabajo". Para ello se apostó un gran número de policías en las puertas de las fábricas y en la zona de surcos. Además, el 18 de noviembre llegaron a la provincia siete nuevos delegados de la CGT, redistribuyéndose algunos hacia Salta y Jujuy. Por otro lado, una fuerte campaña de desinformación anunciaba la vuelta al trabajo en lugares donde esto no sucedia, para desanimar a los huelguistas. Finalmente el propio gobierno exigía a los ingenios que tocasen las sirenas todos los dias.

A pesar de todo, la huelga se mantuvo en la mayor parte de los casos, no obstante algunos éxitos parciales de la estrategia gubernamental. Sin duda la medida de fuerza se estaba desgastando, pero no se avizoraba un final claro. Comenzó entonces la represión directa por medio de los encarcelamientos. Entre el 21 y el 24 de noviembre se apresaron alrededor de 50 obreros azucareros, además de otros sindicalistas y activistas acusados de organizar una huelga general. Este elevado número implicaba la gran mayoría de la dirección de la lucha. El Sindicato de Obreros de Aguilares denunciaba:

Impera en la provincia un clima de terror, ejercido sobre los obreros azucareros por orden del gobernador y ejecutado por los dirigentes de la CGT, quienes, no satisfechos con la clausura de los sindicatos y restringir el derecho de reunión han privado de la libertad a dignos ciudadanos, por el único delito de defender a la hambrienta y sacrificada masa trabajadora azucarera. ${ }^{18}$

En tanto, desde la intergremial se sostenía:

El más somero análisis, pone en evidencia lo inconsistente del fundamento invocado para procederse a la detención de nuestros dirigentes. Hasta ayer, en la delegación del Trabajo

18. La Prensa, 22 de noviembre de 1949. 
y Previsión, y antes, en el propio despacho del gobernador de la provincia, fueron ellos los que llevaron la palabra de los trabajadores del azúcar; [...] ¿Cómo es, entonces, que ahora aparecen esos mismos dirigentes acusados de atentar contra la seguridad del Estado? ${ }^{19}$

Los detenidos eran querellados por violar el decreto 536 de 1945, sobre seguridad del Estado. Pero dentro de esta demanda, ya poco verosímil, se los responsabilizaba de atentar contra el artículo 24 del mencionado decreto que versaba sobre "delitos contra la seguridad exterior del Estado". Tamaña incongruencia fue denunciada por la intergremial, aunque sin respuesta naturalmente.

Los encarcelamientos fueron el golpe de gracia contra la huelga. Los intentos de resistencia en algunos ingenios como San Pablo y Bella Vista, que buscaron erigir nuevas comisiones directivas provisorias, fueron abortados por la policia. ${ }^{20}$ Algunos sindicatos menores, como el de fleteros de San Rafael, comenzaron a negociar directamente la vuelta al trabajo a cambio de la libertad de sus presos. Finalmente, el 28 de noviembre se reunió la intergremial con el gobierno y la CGT, y decidieron el fin de la huelga para el día siguiente. Según la declaración de los trabajadores, tomaban esta decisión por la libertad de los detenidos y por la confianza en la palabra de Perón.

\section{El desenlace: el discurso de Perón, las represalias y el asesinato de Aguirre}

Con el fin de la huelga Perón comunicó que anunciaría personalmente la solución dada al conflicto, a la vez que una explicación sobre el mismo. El mensaje fue leído por el presidente desde Buenos Aires y trasmitido a todo el país por cadena nacional, el 2 de diciembre. La CGT y algunos legisladores provinciales organizaron una gran concentración en la Plaza Independencia, frente a la Casa de Gobierno, para escuchar la palabra del líder. Aquel espacio de gran significado simbólico y concreto, vedado a los trabajadores azucareros durante las huelgas de 1948 y 1949, volvía a abrir sus puertas a los obreros aunque en condiciones claramente diferentes al momento en que la lucha estaba en pie

Numerosos asalariados del sector, junto a otros de la ciudad y adherentes al gobierno se congregaron en aquel acto. El diario La Gaceta publicaba una fotografia con la plaza llena, pero se permitía el siguiente comentario: "Nótese asimismo que algunos de los vehículos enviados a

19. La Gaceta, 22 de noviembre de 1949.

20. La Gaceta, 25 y 26 de noviembre de 1949. 
determinados lugares de influencia de la industria azucarera, regresaban con escasas cantidades de personas y algunos vacíos" ${ }^{21}$ Sin duda hubo algunas resistencias al llamado de Perón, aunque claro que no públicas.

Perón anunció que se aumentaría un $60 \%$ del total de la masa salarial, con retroactividad al 1 de julio, lo cual era uno de los pedidos más fervientes, y cuya redistribución sería discutida posteriormente con una comisión paritaria. Dicha comisión fue nombrada por la intervención de la FOTIA promediando diciembre, la que resolvió dar un monto fijo de $\$ 5,61$ de jornal a todos los trabajadores. Así el salario mínimo aumentó casi un $65 \%$, pasando de $\$ 8,64$ a $\$ 14,25$, mientras el máximo se incrementó en un $32,24 \%$ yendo de $\$ 17,40$ a $\$ 23,01$. Se evidenciaba así que la suba representaba una recomposición salarial de los azucareros respecto de otras industrias, al priorizar el ascenso del piso antes que el escalafón.

No menos importante fue el origen de aquel $60 \%$. Un $25 \%$ sería aportado por la patronal, ya fuesen ingenios o cañeros, y el $35 \%$ restante por el Estado. Del 18\% ofrecido por los primeros durante la negociación, situación que hace suponer que estaban dispuestos a conceder unos puntos más, la diferencia de $7 \%$ no parece sustancial. El brazo que logró torcer la lucha azucarera fue el del gobierno. En el contexto de crisis económica el objetivo era eliminar las compensaciones tras autorizar una suba del precio, pero debieron volver sobre sus pasos.

En contraste, el movimiento obrero azucarero, y el provincial en general, debió pagar un costo político que se evidenció a la postre como mucho más duradero que la solución del aspecto económico. En la jerga coloquial se recuerda como uno de los resultados de la gran huelga, el "descabezamiento" de la FOTIA. Pero este término es insuficiente: la federación y todas sus filiales del país se mantuvieron intervenidas. Terminada la huelga, el cien por ciento de los cargos gremiales fueron caducados y remplazados por "interventores provisorios".

La federación se mantuvo en esta situación durante los siguientes 10 años, trascendiendo al derrocamiento del peronismo, hasta que en 1959 se produjeron comicios normalizadores. Durante ese tiempo, toda elección de delegados o de comisiones directivas, que no fueron numerosas, dejaban el poder de veto en los interventores de la FOTIA, como sucedió en 1952. La delegación regional de la CGT sufrió la misma suerte, como ya mencionamos. El cargo de interventor de la federación azucarera y de la confederación a nivel local quedó en manos de la misma persona, que hasta 1952 fue Antonio Ferrari. No se trató, entonces, de un simple remplazo de "la cabeza", sino de todo el sindicalismo azucarero. Lejos de escuchar el pedido de trasladar la Dirección del Azúcar hacia Tucumán,

21. La Gaceta, 3 de diciembre de 1949. 
que junto con el salarial motivó la gran huelga, el gobierno y la CGT alejaron política y geográficamente la participación de las bases obreras en el lineamiento de las politicas de Estado en el sector.

Además de expulsar a todas las autoridades sindicales de sus cargos, se promovió desde el oficialismo una lista negra. En la misma alocución que planteaba el aumento de salarios, Perón mencionó los nombres de huelguistas que consideraba traidores y advirtió que todo cuanto sostenía estaba documentado en un folleto que haria llegar "a todos". Aquel panfleto apareció en la provincia unos días después, con el nombre de "La TRAICION. De los dirigentes de la FOTIA y la FEIA a los trabajadores del azúcar". En él se reproducía integramente el discurso de Perón, y se le adosaba un complemento del mismo que incluía nuevos nombres junto a las "pruebas irrefutables", que eran tan solo facsímiles demostrando la filiación política de los más reconocidos militantes de la oposición denunciados. El resto era apuntado sin mayor justificación.

Entre el discurso y los posteriores agregados en el folleto, aparecian 132 acusados. 95 eran trabajadores del azúcar, mayormente con cargos sindicales, y el resto de otros gremios, asesores letrados o estudiantes y militantes signados como agitadores. Luego de las palabras de Perón, y más aún tras difundirse el panfleto, varios de los querellados enviaron notas a la prensa pidiendo que se reviese la medida. Pero ni antes ni después de conformada esta lista los damnificados tuvieron derecho a defenderse en los sindicatos ni en el Partido Peronista, de donde fueron echados.

A los pocos días del discurso del presidente, el interventor provincial del partido gobernante Benito Ottonello anunciaba la expulsión del mismo de los afiliados nombrados, y el impedimento de poder incorporarse a quienes no lo eran. El interventor dio una lista de 72 personas, 35 de las cuales pertenecian al partido y fueron exoneradas (no hay datos de los agregados luego, en el panfleto). En el comunicado oficial se explicaba:

Cumpliendo con el deber impuesto por los principios de lealtad hacia la doctrina peronista, el interventor del Partido ha dispuesto la expulsión de las filas partidarias de los mencionados dirigentes, de conformidad a la resolución entregada en la fecha, ya que no es necesario practicar investigación alguna o el estudio de antecedentes, para solicitar una medida que surge en forma imperativa del jefe del movimiento, general Perón. ${ }^{22}$

Hubo además, una fracción de los detenidos y luego imputados como agitadores que sufrió una enconada persecución por parte de la policía. 
Un grupo de aproximadamente 10 sindicalistas de gremios de la capital provincial fueron apresados por intentar organizar una huelga general en solidaridad con los azucareros, días antes de que terminase aquel paro. Al menos la mitad de ellos denunciaron haber sido torturados, sumado a que mediante diferentes mecanismos fueron obligados a abandonar sus cargos gremiales. Pero uno de estos casos cruzó ese límite: el asesinato del mozo Antonio Aguirre, militante del PC, en manos de la policía en el subsuelo de la Casa de Gobierno.

Aguirre fue detenido la madrugada del 28 de noviembre. Cuando se terminaron de liberar todos los detenidos, el $1^{\circ}$ de diciembre, su esposa descubrió que aquel no se encontraba entre ellos. Durante dos semanas se desconoció su paradero hasta que el cuerpo fue hallado en un paraje de Santiago del Estero el 15 de diciembre. Durante ese tiempo, la CGT y el gobierno fogonearon la hipótesis de un autosecuestro en colaboración con sus compañeros del partido. Incluso allanaron varios domicilios de miembros del PC. Pero la investigación judicial, sustentada en los testimonios de otros detenidos que oyeron la golpiza contra aquel, recayó en la detención de varios agentes policiales que terminaron guiando hacia el paradero del cadáver. El 20 de diciembre se produjo una huelga general en repudio a la muerte de Aguirre, a pesar del fuerte boicot contra la misma realizada por la CGT. Esta tuvo incluso diferente grado de adhesión de mozos y otros gremios a lo largo del país. Entre los azucareros solo lograron parar algunos trabajadores en el ingenio Santa Lucía y La Florida, naturalmente en contra del mandato de sus sindicatos intervenidos. En otras zonas azucareras se realizaron paros de 15 minutos. Dos años después, el veredicto del juicio por la causa Aguirre condenaba con prisión en suspenso a los responsables del crimen, dejándolos en libertad (La Nación, 19 de diciembre de 1951).

\section{Reflexiones finales: el lugar de la huelga en la relación entre peronismo $y$ sindicalismo}

Los estudios sobre la gran huelga azucarera ubican la misma dentro del ciclo de huelgas que se extendió entre 1949 y 1951, el cual evidenció los límites de la política distributiva del peronismo y acrecentó el autoritarismo del régimen respecto a los sindicatos. Pero lo interesante radica en examinar el rol de aquellas luchas en la relación entre el movimiento obrero y el peronismo, particularmente respecto a la autonomía de los primeros respecto al Estado y al gobierno.

En el ya clásico debate sobre los orígenes del peronismo, la idea de Gino Germani (1973) de que las masas que abrazaron el naciente movimiento peronista eran heterónomas fue refutada entre otros por Juan Carlos Torre (1990, aunque este autor ya venía trabajando y publicando 
sobre la temática desde mucho antes). Torre sostuvo que quienes primeramente se acercaron al peronismo fueron los viejos sindicalistas que lo precedian, y que su alianza con aquél era un proyecto de autonomía del movimiento obrero. Para este autor, el límite a esa aspiración habría sido la disolución del Partido Laborista y la cooptación de la CGT hacia 1947. Pero la perspectiva interpretativa que se abre con su investigación surge a partir de soslayar el papel del golpe de 1943, y la posterior llegada del entonces Coronel Perón a la dirección de las políticas laborales del régimen, en el proceso de embestida contra la autonomía del movimiento obrero. Ello produjo un cambio en el enfoque del problema: si la autonomía no fue perdida con la llegada del peronismo, entonces se debería rediscutir cuándo sucedió esto, o si realmente sucedió.

Una serie de trabajos posteriores se abocaron a ampliar y profundizar la idea de autonomía sindical durante el gobierno peronista, entre los que podemos nombrar algunos ejemplos paradigmáticos: Susana Pont (1984) planteó que la autonomía política de la clase obrera se vio eliminada junto con el laborismo, pero que aquella se mantuvo en el plano sindical. Louise Doyon (2006) extendió la cronologia trazada por Torre al menos hasta el ciclo de huelgas entre 1949 y 1951, donde la crisis y el aumento del autoritarismo gubernamental habrian, al menos, minado dicha autonomía. Los investigadores tucumanos Gustavo Rubinstein y Florencia Gutiérrez (2013), siguiendo a Doyon, ubican la huelga aquí estudiada como el "límite a la autonomía posible" del sindicalismo azucarero, frontera que habría estado marcada en la "carta natal" de la FOTIA cuando fue fundada en 1944 (Rubinstein, 2005). Otras investigaciones más recientes, como la de Marcos Schiavi (2013), insisten en pretender la existencia de espacios de autonomía del movimiento obrero, considerando que tuvo una "praxis autónoma" en el aspecto económico y político durante los dos primeros gobiernos peronistas.

La presente investigación parte de un replanteo de la hipótesis de Torre, como hemos venido marcando en trabajos anteriores (Piliponsky, 2011b). Desde su inicio, el golpe de Estado de 1943 fue un ataque abierto a la autonomía del movimiento obrero. Si bien un importante sector del sindicalismo existente se alió con el régimen, no se trataba de "la" vieja guardia como caracteriza Torre, pues el movimiento obrero presentaba entonces una marcada heterogeneidad política e ideológica. El gobierno, en alianza con una fracción del sindicalismo, desplazó a los grupos disidentes dentro de los gremios, modificando la relación de fuerzas dentro de los mismos. No sólo la actitud del Estado se transformó con la llegada de Perón, sino también la composición de gran parte de las direcciones obreras. Aquellas razzias fueron una constante durante el peronismo y no se limitaron a los opositores, sino a muchos adherentes a los cuales se les quitaba el apoyo. 
Partiendo de esta hipótesis, la gran huelga azucarera implicó una continuidad de la política intervencionista del gobierno sobre el movimiento obrero, que conllevó la profundización de la misma. No se puede hablar, por lo tanto, de contextos opuestos antes y después de dicho conflicto, o interpretarlo como el momento que marca la pérdida de autonomía. Por el contrario, la persistencia del accionar represivo desde el origen del peronismo se produjo en simultáneo con la cooptación de las masas, lo que ayuda a explicar el proceso de legitimación y "aceptación" de la represión, en este caso sobre los huelguistas de 1949, por parte de los diversos sectores que mantuvieron su filiación con el peronismo.

\section{Bibliografia}

Acha, Omar, y Nicolás Quiroga (2012), El hecho maldito: conversaciones para otra historia del peronismo, Rosario: Prohistoria Ediciones.

Arnedo Álvarez, Gerónimo (1950), Un clamor de justicia en los ingenios. Buenos Aires: Anteo.

Camarero, Hernán (2007), A la conquista de la clase obrera: los comunistas y el mundo del trabajo en la Argentina, 1920-1935, Buenos Aires: Siglo XXI.

Contreras, Gustavo (2012), "Movimiento obrero, sindicalismo y política durante el primer peronismo", Mar Del Plata: UNMDP.

Di Tella, Torcuato S. (2003), Perón y los sindicatos: el inicio de una relación conflictiva, Buenos Aires: Ariel.

Doyon, Louise (2006), Perón y los trabajadores. Los orígenes del sindicalismo peronista, 1943-1955, Buenos Aires: Siglo XXI.

Germani, Gino (1973), "El surgimiento del peronismo: el rol de los obreros y de los migrantes internos", Desarrollo Económico, 13 (51): 435-488.

Iñigo Carrera, Nicolás (2000), La estrategia de la clase obrera, 1936, Buenos Aires: La Rosa Blindada-PIMSA.

Pavetti, Oscar (1999), "Sindicalismo azucarero y peronismo (1949)", en Luis Bonano (ed.), Estudios de historia social de Tucumán, vol. I, Tucumán: Facultad de Filosofia y Letras UNT, pp. 167-206.

Piliponsky, Esteban (2011a), "De las calles a las urnas. Movimiento obrero, izquierdas y laboristas en Tucumán entre octubre del 45 y las elecciones de 1946", en XIII Jornadas Interescuelas/departamentos de Historia. Catamarca.

- (2011b), "Autonomía y estatización. Rupturas en el sindicalismo tucumano frente al fenómeno peronista”, Historia Regional, n 29: 97-122.

Pont, Susana (1984), Partido Laborista: Estado y sindicatos, Buenos Aires: Centro Editor de América Latina.

Pucci, Roberto (2007), Historia de la destrucción de una provincia. Tucumán 1966, Ediciones del Pago Chico.

Rubinstein, Gustavo (2005), Los sindicatos azucareros en los origenes del peronismo; Tucumán: Facultad de Ciencias Económicas UNT. 
Rubinstein, Gustavo y Florencia Gutiérrez (2013), “Alcances y límites de la autonomía sindical. La experiencia de la FOTIA durante el primer peronismo", en César Tcach y Darío Macor, La invención del peronismo en el interior del pais II, Santa Fe: UNL, pp. 245-284.

Schiavi, Marcos (2013), El poder sindical en la Argentina peronista (19461955), Buenos Aires: Imago Mundi.

Torre, Juan Carlos (1990), La vieja guardia sindical y Perón. Sobre los orígenes del peronismo, Buenos Aires: Sudamericana.

$$
* * *
$$

Resumen: La presente investigación buscará reseñar los acontecimientos más destacados de la llamada gran huelga azucarera de 1949, sucedidos mayormente en Tucumán. El foco principal estará puesto en el autoritarismo y la represión desatada por el gobierno, por considerar que este uso de la fuerza marcó el ritmo y la dinámica del conflicto.

Sumado al interés por describir los hechos, el objetivo es ubicar este episodio dentro de la relación del sindicalismo azucarero y tucumano en general con el régimen peronista. $\mathrm{El}$ ataque hacia los trabajadores y sus gremialistas, que ya apoyaban al gobierno y siguieron haciéndolo tras estos acontecimientos, debe ser entendido en el marco de un proceso de permanente imbricación entre coerción y consenso, en donde además se fue legitimando el autoritarismo. Esto no comenzó en 1949 pero sufrió una profundización durante ese año.

Palabras claves: FOTIA - Tucumán - peronismo - huelga.

Abstract: This research will seek to review the highlights of the so named great 1949 sugar strike, which occurred mostly in Tucumán. The main focus will be on authoritarianism and the repression unleashed by the government, considering that this use of force set the pace and the dynamics of conflict.

Adding to the interest in describing the facts, the objective is to place this episode in the relationship of sugar unionism in general and specially in Tucuman, with the Peronist regime. The attack on workers and their union leaders, who already supported the government and continued to do so after these events, must be understood in the context of an ongoing process of overlap between coercion and consent, where the authoritarianism was further legitimized. This did not start in 1949 but suffered a deepening during that year.

Keywords: FOTIA - Tucumán - Peronism - strike.

Recepción: 9 de mayo de 2014. Aprobación: 16 de junio de 2014 . 